\title{
Exploring modes of engagement within reform-oriented primary mathematics textbooks in India
}

\author{
Meghna Nag Chowdhuri ${ }^{1}$ iD
}

Accepted: 25 November 2021 /Published online: 19 January 2022

(c) The Author(s) 2022

\begin{abstract}
In India, a curriculum reform inspired by critical perspectives has sought to transform primary mathematics teaching and learning. It is aimed at strengthening socio-culturalpolitical connections between school mathematics and students' life experiences, thereby challenging traditional textbook culture. At the same time, this initiative has retained the textbook as a vehicle of reform while seeking to subvert many of its established conventions. Guided by Remillard's idea of modes of engagement, this paper analyses the innovative Math-Magic textbooks associated with the Indian National Curriculum Framework. It investigates how these textbooks represent and communicate the framework ideas, focusing on key curricular elements and on the teacher as reader. Analysing the 'voice' and 'structure' of the textbooks as well as the 'contexts' used, it is revealed that they use a radically unique voice to introduce school mathematics while also attempting to use authentic and socially relevant contexts within their tasks. However, they have limited structural support to communicate these ideas clearly to the teacher-reader. The paper has implications for studying reformed textbooks in primary school mathematics in the Global South, where they remain the main teaching resource for teachers. Further, by focusing on 'context', the notion of modes of engagement within textbooks is extended through socio-cultural perspectives.
\end{abstract}

Keywords Mathematics textbooks $\cdot$ Textbook analysis $\cdot$ Reforms in India $\cdot$ Reform textbooks $\cdot$ Contexts in textbooks $\cdot$ Primary textbooks

\section{Introduction}

Curricular reforms, both in India and globally, have attempted to transform the ways in which mathematical teaching and learning take place. One widely used strategy to achieve such a transformation involves developing mathematics textbooks based on the principles of reform. Typically, these principles are based on contextual policies, educational ideologies and significant research findings in mathematics education. For instance, in the 1990s, with the introduction of the National Council of Teachers of Mathematics (NCTM)

Meghna Nag Chowdhuri

nc.meghna@gmail.com

1 Institute of Education, University College London, London, UK 
Standards in the United States (US) and Canada (NCTM, 1989), a number of textbooks and other curricular materials were designed to promote reforms that included a focus on problem-solving and challenging mathematical tasks. The Standards influenced several other reforms across the world (see Fan \& Zhu, 2007). Similarly, in the Netherlands, the Realistic Mathematics Education (RME) movement led to Dutch textbooks designed on RME principles (Gravemeijer, 2014).

In this paper, the curricular reforms in India under the National Curriculum Framework (NCF-2005) are investigated, with the main focus being on the associated mathematics textbooks. Based on these reforms, Math-Magic textbooks (Books 1-5) were developed and introduced by the National Council of Educational Research and Training (NCERT) (NCERT, 2006a, 2006b, 2007a, 2007b, 2008). Because the NCF reforms sought to establish stronger connections between school mathematics and the life experience of students, as well as challenge the overuse of textbooks themselves, the question that arises is how such reforms can be conveyed within textbooks. In addressing this question, it is important to recognise that these texts have audiences and modes through which these audiences are engaged (Remillard, 2011). This paper explores these matters by addressing the following specific research question.

How are socio-critical ideals of the Indian National Curriculum Framework represented and communicated within the associated primary mathematics textbooks?

\section{Math-Magic textbooks: challenging textbook culture and adapting a socio-cultural approach}

A key focus of NCF-2005 was to challenge the predominance and overuse of the textbook itself. One of its guiding principles was "(iii) enriching the curriculum so that it goes beyond textbooks" (NCERT, 2005, p. viii). This appeal for textbook reforms needs to be understood within the larger context of textbook culture in India. In his two seminal articles, "Textbook and Educational Culture" (1986) and "Origins of "Textbook Culture", (1988), Krishna Kumar discussed the central role of textbooks in the Indian educational system. Textbook culture refers to the dominance of official state prescribed textbooks, which defines every aspect of school teaching and learning. This dependence on textbooks for centralised and authorised forms of knowledge has been documented in other studies as well (see Clarke, 2001; Sarangapani, 2003; Vijaysimha, 2013). Regarding which, Vijaysimha (2013) found that, via textbook culture, a distinction was maintained between school knowledge and outside school knowledge in science classrooms.

NCF-2005 directly addressed issues that accompany textbook culture, by calling for diversification in terms of resources (and moving away from one textbook) as well as the need to conceptualise a 'good textbook'. It claimed that a good curriculum resource "leads the child to interact with their environment, peers, and other people rather than be a selfcontained transferrer of knowledge as a finished product" (p. 38). Accordingly, a key aim in the reforms for mathematics education was to connect school mathematics to students' lives. NCF-2005 viewed this through the lens of both critical pedagogy and ethnomathematics. For instance, it pointed to the absence of "social concerns in designing curricula, which would enable children questioning received gender ideologies and the absence of reference to women's lives in problems" (p. 7). Furthermore, through a lens of ethnomathematics (d'Ambrósio, 2006), the linking of mathematics and students' lives also meant 
bringing to the fore "folk algorithms and mathematics that people use" (p. 11). Consequently, an active effort was made to develop and introduce textbooks that were aligned with these aims of NCF-2005. NCERT came out with a series of primary school textbooks (Book 1 to Book 5) based on the principles espoused in NCF-2005, named Math-Magic (NCERT, 2006a, 2006b, 2007a, 2007b, 2008). The Math-Magic textbooks were developed in a unique political context, as an attempt to rethink mathematics teaching (Rampal, 2015; Rampal \& Makar, 2012; Rampal \& Subramanian, 2012; Syeed, 2018). Indeed, these textbooks were commended by several newspaper articles and reviewers (see Mukherji \& Mukul, 2009; Sengupta, 2007; Subrahmaniam, 2005; Tripathi, 2006) for having attempted a unique approach. Within this background, this paper investigates the ways in which these ideals were reflected in the text, which requires a devising of a relevant framing for textbook analysis.

\section{Literature review}

Textbooks are not just a collection of a certain type of content knowledge that 'ought to be taught', but also present a mode of engagement (Remillard, 2011) through which the readers interact with this knowledge. Remillard (2011) identified voice, medium, look, structure and genre of the text as the key modes of engagement to understand how teachers interact with texts. As expressed in the sections above, the NCF-2005 reforms attempted to challenge the dominance of textbook culture and introduce mathematics as a socio-culturally rooted subject. Three modes of engagement were chosen as being most relevant to the reforms that would guide Math-Magic textbooks: voice, structure and context. In the next sections, I detail why and how these constructs were used.

\subsection{Voice of the text}

With the emphasis on rejecting textbook culture, the reforms were dedicated to challenging the textbook's position as an authority in mathematical knowledge. One way of doing so is to modify the 'voice' of the text, which is a tactic that has been used in mathematics textbooks for a long time. For example, Fauvel (1991) described how voice differed in early mathematics texts (sixteenth century to twentieth century) and defined the relationship between the mathematical knowledge and the reader. It thus becomes crucial to explore how (or if) voice has been used as a means of influencing the pedagogical interaction between the author and reader in these Math-Magic textbooks. According to Remillard (2005), "voice refers to how the authors or designers are represented and how they communicate with the teacher and the students" (p. 233). Hence, the analysis of the 'voice' of a textbook is typically about investigating the ways in which the authors present themselves to the reader and constructs their relationship. For example, Herbel-Eisenmann (2007) used Rotman's (1988) idea of 'thinker' and 'scribbler' as roles assigned to the reader. While scribbling is an exclusive activity, where the reader is supposed to work on their own to apply and use what they know, thinking is an inclusive activity involving a wider community that includes some level of dialogue or communication. Other studies have focused on other aspects of voice. For example, Morgan (2016) explored how humans are represented in the voice of the text in relation to the mathematical activity. Furthermore, Wagner (2012), in his analysis of his self-authored textbook for the Bhutanese curriculum, analysed the 'openness' of the texts (using Eco's (1979) notion of the linguistic openness of texts) 
to identify the extent of interpretive agency it gave to the reader. These are useful perspectives to study the voice of mathematics texts. Apart from the voice used within student textbooks, some studies have also analysed the voice of teacher guidebooks. For example, in Ahl and Koljonen's (2017) analysis of Swedish teacher guidebooks, by analysing the use of personal pronouns and imperatives, they found that these textbooks tended to speak through the teachers via teacher scripts, rather than to them. As can be seen in later sections, I too focus on both how the textbook addresses students as well as teachers.

\subsection{Context in text}

The use of contextual themes within textbooks is common and has been explored in various textbook analysis studies (Barcelos Amaral \& Hollebrands, 2017; Li, 2000; Wijaya et al., 2015). These studies, however, have mostly been focused on the cognitive complexity of contextual tasks. For example, Barcelos Amaral and Hollebrands' (2017) study of US and Brazilian textbooks analysed the cognitive complexity of contextual tasks that might have had superfluous information. However, the socio-cultural-political aspects of textbooks, which are crucially important in the Indian context (as discussed above), are less widely researched in the Anglophone literature. As Fan et al. (2013) pointed out in their review of textbook research, while attention to social issues of gender and equity was given importance in earlier studies (Clarkson, 1993; Garcia, 1990), more recently, this has not been the case. This waning emphasis on social issues in mathematics textbook analysis could also be because of the lack of attention to these aspects in the US reforms that have influenced reform worldwide. Apple (1992) argued that the mathematics reforms in the US have not paid sufficient attention to issues of equity and social justice. This distinction between 'reform' curriculum and 'critical' curriculum was operationalised in Brantlinger's (2011) analysis of the geometry curriculum. He viewed critical/radical mathematics aimed at social justice as being in opposition to both traditional and Standards-based reform mathematics in the US.

In India, notions of critical mathematics as well as ethnomathematics, which foreground issues of equity and social justice, are central to the mathematics reform, as promoted by NCF-2005. This is similar to some post-colonial African countries that have attempted to reform their mathematics curricula from a social justice perspective. Regarding which, scholars, including Schubring (2017), Gerdes (1996), and Vithal and Skovsmose (1997), have pointed to the need for critical and post-colonial perspectives to understand curriculum development in the Global South. There have been several studies in African contexts focusing on the real-life, critical and ethnomathematical aspects of the curriculum (Bowie, 2014; Draisma, 2018; Mbekwa \& Julie, 2009; Nyabanyaba, 1999). For instance, in Namukasa's (2018) paper on the analysis of Ugandan reform-based textbooks, she used a postcolonial and critical perspective to investigate the ways in which the textbooks have been designed. Thus, in these studies, it can be seen that 'context' continues to be discussed, but unlike earlier mentioned studies that were focused on cognitive demands, questions of relevance and social redress have come to be considered more important.

In this paper, I foreground the notion of context from a social perspective. The idea of context in mathematics education is highly complex. Terms, such as real, realistic contexts, real-life contexts, everyday life contexts and daily life, are all often used interchangeably in the literature (Palm, 2006). Many scholars have engaged in attempts to make contexts authentic (Palm, 2006) and meaningful (Van den Heuvel-Panhuizen, 2000). Furthermore, from the perspective of ethnomathematics and culturally responsive mathematics, context 
has been embedded to reflect different mathematical traditions around us (d'Ambrósio, 2006; Greer et al., 2009). Gutstein (2006) also talks about using context in mathematics education for social justice, pointing out the social positioning and roles of different social groups engaged in mathematical activity. Thus, the role and meaning of context can be different when viewed through different mathematics education traditions. In this paper, Borasi's (1986) broad definition of context as "the situation in which a problem is embedded" (p. 128) is used. Context can be presented not just in forms of varied texts, but also illustrations and photographs of everyday life, adding complexity to how context is portrayed.

\subsection{Structure of the text}

The structure of a textbook defines how readers engage with it. In India, textbooks have often been criticised for being structured as teaching scripts of authorised knowledge (see Mili \& Winch, 2019). As the NCF-2005 reforms were keen to reject the use of textbooks as mere scripts (devoid of any input from students or teachers), it becomes crucial to explore what kind of structure the Math-Magic textbooks offer. The structure of the mathematics textbook has been explored in the research literature in various ways. For example, Valverde et al. (2002) focused on the "form and style not the substance" (p. 17) to understand how text was structured. They analysed both the "macro-structure" and "micro-structure" of the textbook. While the macro-structure referred to the physical features of the textbooks, content presentation and expectation for performance, the microstructure pertained to the lesson structure in terms of the blocks of "narratives, exercise/ question sets, activities, worked examples" (p. 144). Furthermore, within curricular reforms, the ways in which textbooks are structured can also be deliberately altered. For instance, Ben-Peretz (1990) spoke about two types of curricula "structured, sequential" or "unstructured, modular" (p. 28) based on the ideals of pedagogical reforms. Namukasa (2018) analysed the structure of mathematics textbooks to explore how they reflected the national Ugandan reforms. She found that typically their structure had remained: "background, content explanation, a few examples followed by exercises then followed by review exercises" (p. 945). However, there have been some textbooks that delay providing explanation and present the content in an interactive manner. Comparing traditional and reform-based textbooks in the US, Sood and Jitendra (2007) identified key structural differences. They explored whether the instruction within the textbook was provided conspicuously or not, whether scaffolding supported the instruction (feedback, representations) and, finally, whether there were opportunities for students to review what they had learnt (within-lesson practice, across-lesson practice). Under this lens, the structure of textbooks also includes the level of explicit instruction, feedback and opportunity for practice, which in turn become prompts for teachers. In this paper, I explore these microstructures embedded as prompts within the texts.

\section{Research methods}

\subsection{Sample}

This paper focuses on Math-Magic textbooks for grades 4 and 5 (NCERT, 2007b, 2008), which can be found online (https://ncert.nic.in/textbook.php) (I encourage readers to open the texts online and use them as a reference while reading this article). As this analysis was 
Table 1 Math-Magic Book 4 and Book 5 contents page mapped with mathematical topic

\begin{tabular}{|c|c|c|c|c|}
\hline $\begin{array}{l}\text { Chapter } \\
\text { number }\end{array}$ & Chapter name & Implicit mathematical topic & $\begin{array}{l}\text { Number } \\
\text { of pages }\end{array}$ & $\begin{array}{l}\text { Number } \\
\text { of tasks }\end{array}$ \\
\hline \multicolumn{5}{|l|}{ Book 4} \\
\hline 1 & Building with bricks & $\begin{array}{l}\text { Thematic: geometrical patterns based on } \\
\text { symmetry }\end{array}$ & 12 & 11 \\
\hline 2 & Long and short & Measurement of length & 10 & 14 \\
\hline 3 & Bhopal trip & $\begin{array}{l}\text { Thematic: four operations, measure- } \\
\text { ment, number estimation }\end{array}$ & 12 & 9 \\
\hline 4 & Tick tick tick & Time & 17 & 9 \\
\hline 5 & The way the world looks & Space & 8 & 6 \\
\hline 6 & The junk seller & Thematic: multiplication, division, loan & 9 & 13 \\
\hline 7 & Jugs and mugs & Measurement of volume & 12 & 13 \\
\hline \multicolumn{5}{|l|}{ Book 5} \\
\hline 1 & The fish tale & Thematic chapter & 15 & 15 \\
\hline 2 & Shapes and angles & Shapes and spatial understanding & 18 & 19 \\
\hline 3 & How many squares? & Area and perimeter & 16 & 14 \\
\hline 4 & Parts and wholes & Fractional numbers & 21 & 30 \\
\hline 5 & Does it look the same? & Symmetry of shapes & 16 & 11 \\
\hline 6 & Be my multiple, I'll be your factor & Factors and multiples & 12 & 14 \\
\hline 7 & Can you see the pattern? & Patterns & 13 & 14 \\
\hline
\end{tabular}

a part of a larger doctoral study, which included analysis of teachers' textbook enactments (Nag Chowdhuri, 2021), only the chapters for which lessons were observed were included in the study. Overall, in the seven chapters analysed of Math-Magic Books 4 and 5, there were 75 and 117 tasks, respectively. These chapters covered a variety of mathematical concepts (mapped based on the chapter content) (see Table 1). While most of the chapters contained tasks around one mathematical topic, there were also some that integrated different mathematics topics. This includes Chapters 1, 3 and 6 in Book 4 and Chapter 1 in Book 5 (highlighted in Table 1).

\subsection{Unit of analysis}

The analysis of the textbook, for which a three-part framework of voice-context-structure was used, required identifying a suitable unit of analysis, and the 'task' was chosen as the appropriate one. Conceptually, as defined by Watson and Thompson (2015), a task is a "written presentation of a planned mathematical experience for a learner, which could be one action or a sequence of actions that form an overall experience" (p. 143). Operationally, within each chapter, a task was identified as the content between two consecutive headers. To identify markers of voice, context and structure within the text, the tasks were further broken down into components of two types-eliciting and non-eliciting components, the former being components of the tasks that sought to elicit some response from the reader (i.e., student) and the latter texts which did not require any response. As shown in Fig. 1, aspects of voice, structure and context were identified within these components. For example, voice was analysed by exploring the eliciting components (type of task) as well as non-eliciting components (teacher guidelines). Regarding context, the focus was on 


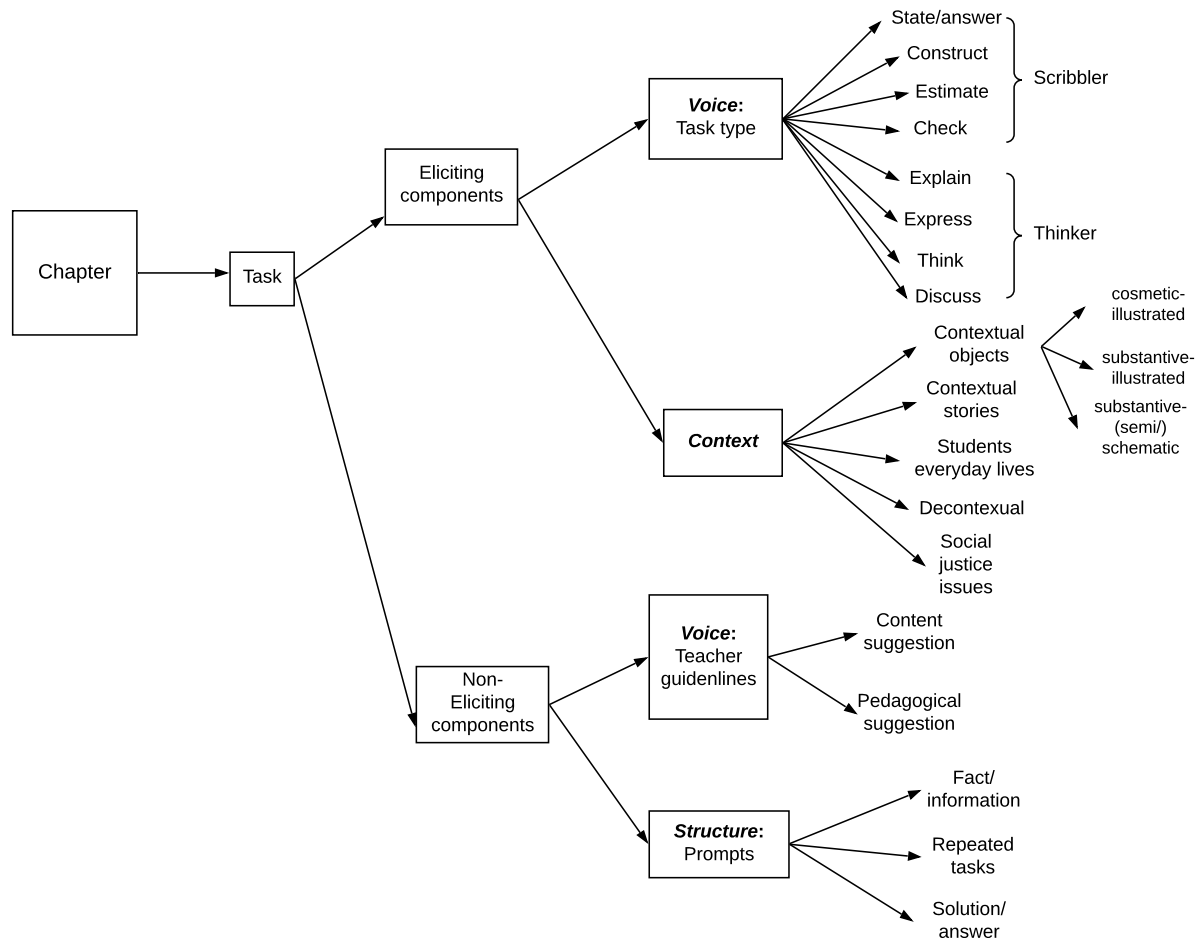

Fig. 1 Coding process of the textbook

the eliciting components to identify contextual objects, stories, students' everyday lives and social justice issues. Finally, to analyse the structure of the textbook, both prompts within non-eliciting components as well as the task headers and task sequencing were analysed.

\subsection{Coding scheme}

When coding textbook tasks, several approaches can be taken. A rating scale can be used (Bryant et al., 2008), the number of occurrences can be counted (Remillard, 2011; Herbel-Eisenmann, 2007), or a binary value (yes/no) can be ascribed. In this analysis, I used binary values (yes/no) to mark the presence of the abovementioned categories (Fig. 1) and then counted them. For example, if an eliciting component asked students to explain their answer, a presence of 'explain' was marked within the task (see Table 2). All tasks were marked for multiple categories, which were not mutually exclusive. Counting these markings supported the understanding of the voice of the text. To analyse the textbook's structure, repeated task headers were identified and compared with the total number of tasks. In some cases, coding occurred in several stages. For example, for context analysis, first, whether the text had any 'context' embedded in it was ascertained. After that, contextual objects/stories/social justice issues/everyday lives were identified. In cases where there was the presence of contextual objects, these were further coded according to whether these 
Table 2 Types of eliciting components of the task

Types of direct questions

State Eliciting questions seeking response from students in written or oral work form. The response can be obtained using any mathematical skill or procedure (by measuring, reading the time, using multiplication) and could be in the form of written numbers, oral, by drawing, making a line, marking the correct answer, etc.

Construct Eliciting questions, where students engage with a task in a format other than answering questions, thinking, expressing experiences or justifying their product or process (in the textbook or notebook). These require students to use or (and) create additional materials and artefacts, play games or conduct experiments

Estimate Eliciting questions asking students to guess the answer or process in the task

Check Eliciting questions asking students to verify or check the answer or process in the task

Explain Eliciting questions (specified or generative) seeking an explanation or justification of the mathematical thinking or process underlying the solution of the task

Express Eliciting questions (specified or generative) inviting students to express their interests, thoughts or experiences. This is different from the explanation task, which is specifically asking for justification or explanation for the mathematical process, whereas these are mostly to engage students in thinking, feeling and reflecting on experiences from out-ofschool contexts

Think Eliciting questions asking students to think about the answer or process in the task

Discuss Eliciting sub-tasks asking students to discuss (among peers or with the teacher) the answer or process in the task

were for cosmetic purposes or substantive purposes (to support in the task's solution) and whether these were schematised or illustrations/drawing/photos. Fig. 1 shows the coding scheme of the analysis (and its different levels), which reflects how the textbook was deconstructed with the focus on a voice-context-structure framework. Table 3 also provides an example of how a task (in this case Magic Top) was coded using the framework described above.

\section{Magic Top}

Let us make a magic top.

Take a cardboard piece.

Draw a circle of radius $3 \mathrm{~cm}$ and cut it out.

Divide the circle into 8 equal parts. Now each part is $1 / 8$ of the circle.

Colour $2 / 8$ red, $1 / 8$ orange, $1 / 8$ yellow etc. as shown here. Push a matchstick through the centre of the circle.

Your magic top is ready. Spin it fast!

What do you see? Can you see all the colours? Write what you see in your notebook.

\section{Book 5, Chapter 4, page 52}

In the task "Magic Top" (chapter: Parts and Wholes), the first five statements are instructive in nature. They provide steps for constructing a magic top. As this requires the reader to use external materials to construct a top, the task was marked as 'construct' (see Tables 2 and 3). Furthermore, in the last statement of the task, the students are asked to interpret what they see, which suggests 'expressing' using their experience of playing with the top and consequently marked as 'express'. Finally, the reader is asked to use their notebooks and answer in a written format, making it a 'state' type 
Table 3 Example of coding for the task "Magic Top"

\begin{tabular}{lll}
\hline Codes & Sub-codes & Magic Top \\
\hline Task type & State/answer & Yes \\
& Construct & Yes \\
Estimate & No \\
Check & No \\
Explain & No \\
Express & Yes \\
& Think & No \\
& Discuss & No \\
& Contextual objects & Cosmetic-illustrated and \\
Context & & substantive- (semi) \\
& & schematic \\
& Contextual stories & No \\
& Students everyday stories & Yes \\
& Decontextual & No \\
Teacher guidelines & Social justice issues & No \\
Prompts & Content/pedagogical suggestion & No \\
& Fact/information & No \\
& Repeated tasks & No \\
& Solution/answer & No \\
\hline
\end{tabular}

task. Next, I coded the nature of context within the task. The task does not include a story format but introduces a context which (presumably) students would have experienced in their everyday lives (playing with a top). Thus, the task was marked as including 'students' everyday lives.' The task is also accompanied by two illustrations which showed children playing with a top (cosmetic-illustrated). However, the top shown in the illustrations is schematically drawn and not illustrated-showing a circle with eight equal parts. Presumably this is provided to support students in their understanding of how a circle with 8 equal parts looks (which is very different from a 'real-life' top). Thus, illustrations were marked as being both cosmetic-illustrative and substantive semi-schematic in nature. Finally, there are no embedded issues of social justice, no textual prompts (apart from the illustrations themselves) and no teacher guidelines included.

Note that coding using this framework (Fig. 1) while feasible was far from straightforward. The language of the text is open and thus also open to several interpretations making identifying and marking these tasks an interpretive process. For example, in the above example, students are asked to observe the top and write down what they see. This could be marked simply and solely as 'state' (interpreted as a yes/no question-“Can you see all colours?") or 'express', as the task also provides a space for students to express different ideas about what they see. Similarly, for the illustrations, while the image includes children playing, it also includes a particular schematised drawing of the circle-making it open to interpretations. For such tasks, I marked all the categories, so that a wider range of interpretations could be accommodated in the analysis. 


\section{Findings}

\subsection{Voice of the text: opening the text to challenge its authority}

Almost all the tasks have eliciting components, which directly expect responses from students. Only three tasks in Book 5 (out of 117) and two tasks in Book 4 (out of 75) do not have any of these. As shown in Table 2, there are different ways in which students were expected to address these eliciting components. In the following example from Book 4, students are asked to 'estimate' their own classroom's height and then to 'calculate' the approximate height of a historical monument and, finally, to 'explain' their answers. In the textbook, the task is accompanied by a photograph of the monument itself. This is an example of a typical task that engages the student-reader using different voices.

\section{How Many Rooms High?}

The Qutab Minar is 72 metres high.

About how many metres high is your classroom?

Guess how many rooms, one on top of the other, will be equal to the Qutab Minar.

Explain how you made a guess.

\section{Book 4, Chapter 2, Task 10, page 19}

These different questions identified in the textbook are classified based on whether they are 'thinking' or 'scribbling' questions (Rotman, 1988). While there are components of 'state/ answer' in $90 \%$ of the tasks in both Book 4 and Book 5, it is important to note that several other scribbler type questions, including 'estimation', are also commonly posed in the textbook (Table 4). However, a small proportion of the tasks (between 3 and 19\%) include 'thinking' questions. These more explorative questions expect students to engage with mathematics in a more collective manner.

As Herbel-Eisenmann and Wagner (2007) pointed out, the audience with whom the reader is supposed to share their thinking is equally important. Most of the tasks do not explicitly specify with whom discussing/explaining/thinking/estimating is to be shared. However, implicitly tasks have been set up as activities where humans are shown as being active agents of doing the mathematics. For instance, characters are introduced either doing the mathematics, or talking about it, or thinking about it. This strategy, as Morgan (2016) discussed, aims to break the absolutist understanding of mathematics as occurring in esoteric spaces (or students' individual minds), by making it a real-world activity. For example, in a task in Chapter 3 of Book 5 (pages

Table 4 Types of expected student engagement

\begin{tabular}{llllll}
\hline & & $\begin{array}{l}\text { Book 4 } \\
\text { Total }\end{array}$ & $\begin{array}{l}\text { Book 4 } \\
\text { Percentage }\end{array}$ & $\begin{array}{l}\text { Book 5 } \\
\text { Total }\end{array}$ & $\begin{array}{l}\text { Book 5 } \\
\text { Percentage }\end{array}$ \\
\hline Scribbler & State/write & 68 & $91 \%$ & 105 & $90 \%$ \\
& Construct & 10 & $13 \%$ & 19 & $16 \%$ \\
& Estimate & 19 & $25 \%$ & 13 & $11 \%$ \\
\multirow{5}{*}{ Thinker } & Check & 7 & $9 \%$ & 4 & $3 \%$ \\
& Explain & 7 & $9 \%$ & 9 & $8 \%$ \\
& Express & 14 & $19 \%$ & 5 & $4 \%$ \\
& Think & 6 & $8 \%$ & 4 & $3 \%$ \\
& Discuss & 7 & $9 \%$ & 6 & $5 \%$ \\
\hline
\end{tabular}


41-42), two children - Sameena and Sadiq - are depicted having a conversation about the mathematical topic of triangles (with dialogue boxes and illustrations of the children and the triangles). This implicitly indicates that mathematical activity goes beyond individual students' exclusive scribbling work and also takes place collaboratively as an inclusive activity.

Example 1:

Children should be encouraged to estimate first and then find out the answer using any method they want. It is important to discuss the methods children use to solve a problem.

Book 4, Chapter 3, page 23

\section{Example 2:}

The colouring circle game and many such activities should be done in class. The follow-up discussions for all these activities will play a major role in developing children's conceptual understanding about fractions.

\section{Book 5, Chapter 4, page 61}

It is interesting that, while the voice of the text (addressed to the student) appears to have the aim of opening up the text, the teachers' notes seem prescriptive, in terms of giving directions on how the tasks 'should' be done. While the teachers are told that "it is important to discuss the methods children use to solve a problem," their role in this discussion is not explicated. Are they expected to have to choose the correct answer, lead the discussion towards an efficient solution and/or ensure participation of all students? What would be the purpose of the discussion? Neither the task's intentions nor the role of the teacher are clarified in these teacher notes, which seem to simply repeat or extend the voice of the task itself.

Here, Wagner's (2012) analysis is very useful. In his work, he pointed out that even a seemingly open text does not necessarily quell seduction. By seduction, Wagner was referring to how the text might lead to the construction of "an ideal child" (p. 163), despite attempting openness. In the case of Math-Magic, there is an imagined ideal child, who interacts with mathematics in all these multiple ways, and teachers are recommended that they 'should' lead their teaching towards that. Thus, the openness is an "illusion" (p. 164), as the path has already been determined in the curriculum. Wagner (2012) suggested different ways of addressing this issue. His most crucial recommendation was making the author's voice visible and "critical" (p. 167). He pointed to Fauvel's (1991) analysis of English textbooks, where the author provided examples of how the textbook itself became a critic and questioned the appropriateness of mathematical procedures (within themselves) explicitly. The Math-Magic series does include open elements (as shown above), but there are few critical voices in the text. While the textbook encourages the student to 'think' about the tasks, there is limited acknowledgment of contestations that might arise during these task enactments. Thus, the author's voice critiquing and clarifying these open elements is unavailable.

\subsection{Contexts within the text: creating authentic "real-life" experiences}

In these textbooks, almost all tasks contain contextual elements (Table 5). Only four in Book 4, and 29 in Book 5, were coded as being completely decontextual, with no presence of the above contextual elements. This is crucial, because it highlights that the textbook 
Table 5 Use of context in the textbooks

\begin{tabular}{lllll}
\hline Types of context & $\begin{array}{l}\text { Book 4 } \\
\text { Total }\end{array}$ & $\begin{array}{l}\text { Book 4 } \\
\text { Percentage }\end{array}$ & $\begin{array}{l}\text { Book 5 } \\
\text { Total }\end{array}$ & $\begin{array}{l}\text { Book 5 } \\
\text { Percentage }\end{array}$ \\
\hline Students everyday contexts & 34 & $45 \%$ & 20 & $17 \%$ \\
Contextual stories & 37 & $49 \%$ & 48 & $41 \%$ \\
Contextual objects & 56 & $75 \%$ & 99 & $85 \%$ \\
Social issue theme & 9 & $12 \%$ & 7 & $6 \%$ \\
\hline
\end{tabular}

authors have actively attempted to integrate context in almost all the tasks. What follows in this section is different types of identified contexts being discussed.

There are tasks, for which students are expected to interact directly with their environment and everyday lives to help with the task formulation as well as its solution (45\% in Book 4, 17\% in Book 5). A common type of such a task is where they are asked to 'find' something from their lives, such as heights of their peers, different objects in their homes/ schools, etc. and then to address the attendant questions. For example, the following task (which is accompanied by illustrations of different types of packets and bottles) asks students to "look around" and find packets that contain different types of liquids. These tasks enable students to bring their own individual experiences/understanding into the classroom, along with the opportunity to 'author' their own tasks, rather than relying solely on the textbook's pre-formulated questions.

\section{Look Around}

Look at these pictures. Now look for some other things we get in packets or bottles like these. Make your own list.

\begin{tabular}{lc}
\hline Packet & How many mL or L? \\
\hline Milk & $500 \mathrm{~mL}$
\end{tabular}

Book 4, Chapter 7, page 74

In both Books 4 and 5, several real-life contextual stories are used in the tasks. Many of these 'contextual stories' are similar to a traditional word problem (Verschaffel et al., 2000), where students are expected to strip the context from the problem and then solve it mathematically. For example:

Manju had a chocolate. She gave one-fourth of it to Raji, one-third to Sugatha and one-sixth to Sheela. She ate the remaining part. How many pieces of chocolate did each get? Write here.

Raji___ Sugatha___ Sheela ___ Manju

What part of the chocolate did Manju eat?

Book 5, Chapter 4, page 52

Such tasks, common in mathematical teaching, provide enough contextual/mathematical information to solve the problem. However, the textbook also makes an explicit effort to create 
richer contexts, often spread over several tasks-building from one to another. For instance, the entire chapter "Trip to Bhopal" (Book 4, Chapter 3) is based around the context of a school trip. The tasks move along probing different questions to the reader at different points of the trip: when school children board the bus, when they stop for refuelling, lunch time and visiting different attractions. One particular task, "To Bhimbhetka", provides details about prehistoric caves of India the students are visiting (see below). This task is accompanied by photographs of the caves. Such information is not necessary from the perspective of solving any particular 'mathematical' problem, but it does provide an example of a mathematical discourse (between student and teacher) around the contextual theme of the chapter.

\section{To Bhimbetka}

After the buses are refilled, the journey starts again. Now the children are told that they are stopping at Bhimbetka.

Anjan - What is Bhimbetka?

Ms. Raina - It's a place with lots of caves and cave-paintings made by people ten thousand years ago.

Sumonto - Ten tho...uu...saa...nd years! I cannot even think of one thousand years back!

Gopi - Oh! One thousand years is a big thing, I can't even think of one hundred years.

Gauri - I can think of 100 years because my father's grandmother is 100 years old.

Manjeet - That means those caves are almost hundred great grandmothers old!!

Everybody bursts into laughter - $\mathrm{Ha}$ ! Ha! Ha!

\section{Book 4, Chapter 3, page 28}

Gerofsky (2004), using literary genre studies, defined word problems as having a threecomponent compositional structure: "set-up", "information" and "question" (p. 27). On the other hand, Beswick (2011) defined authentic contextual tasks as those that contain "extra mathematical information" (p. 45). In Book 4, 25\% of the tasks with contextual stories include such word problem-like tasks and $14 \%$ in Book 5. This discussion is particularly important as teachers are often more used to the 'word problem genre,' whereas the use of 'extra mathematical information' in richer contextual tasks is open to interpretation. There are also theoretical concerns. Gerofsky (2010) warned about the impossibility of this idea that "real life" can be authentically translated into a school mathematics word problem, because of the distinct nature of school and out-of-school mathematics. Real-life mathematics represented in the school setting can never become the real problem itself, and thus, a fundamental dissonance exists between the two. The author further argued that the 'real-life' stories in mathematics school settings will always become more like the 'word problem genre' than the real problem in a real setting. Overall, there is an attempt to move towards authentic contextual stories while also including several traditional word problems.

Another aspect of the textbooks that is immediately striking is the use of contextual objects in forms of illustrations, graphics and photographs throughout. Almost every task has accompanying illustrations. Many of them are only for aesthetic purposes and are not used directly to support the task (Table 6). However, a sizeable number of illustrations (both illustrated and schematised) are used directly to support the eliciting components of the text. In other words, these illustrations are crucial parts of the task itself, and some level of interpretation of these is required to address the questions. For example, in the above task "To Bhimbetka" (page 29), students are eventually asked to look at the accompanying photograph of the caves and count how many deer and bison are drawn in the caves. From 
Table 6 Types of illustrations and the proportion of their presence

\begin{tabular}{lllll}
\hline Illustrations/graphics & $\begin{array}{l}\text { Book 4 } \\
\text { Total }\end{array}$ & $\begin{array}{l}\text { Book 4 } \\
\text { Percentage }\end{array}$ & $\begin{array}{l}\text { Book 5 } \\
\text { Total }\end{array}$ & $\begin{array}{l}\text { Book 5 } \\
\text { Percentage }\end{array}$ \\
\hline Cosmetic & 34 & $45 \%$ & 32 & $27 \%$ \\
Substantive-illustrated & 16 & $21 \%$ & 31 & $26 \%$ \\
Substantive- (semi/) schematic & 12 & $16 \%$ & 55 & $47 \%$ \\
Total & 56 & $75 \%$ & 99 & $85 \%$ \\
\hline
\end{tabular}

a cognitive perspective, recent studies have found that using such depictive representations (rather than descriptive) can make contextual tasks more accessible for students (see Hoogland et al. 2018). Thus, the use of photographs can be particularly useful for students.

These textbooks include visual representation of contextual objects with varying degrees of authenticity. While photographs and illustrations are used for some tasks (as discussed above), schematic versions of real-life objects are also used in some instances. For example, in a task in Book 5, students are asked to find the area of a stamp drawn on squared grids: "How many squares of one centimetre side does stamp A cover?" (Book 5, Chapter 3, page 35). Book 4 contains very few schematised versions of objects $(16 \%)$, while in Book 5, the authors take a much more schematic approach (47\%). In such cases, the readers are to ignore these 'real-life' aspects and focus on the mathematical properties of the illustrations. The textbook, thus, uses multiple ways of representing and presenting interactions between 'real-life' and 'mathematics'. An example of this interaction and tussle (between 'authentic' and 'schematised') is reflected in the illustration in Book 5, Chapter 6, page 93, where a more schematised arrangement of pebbles has been superimposed on top of a hand-drawn illustration.

Social themes chosen as context can play an important role in legitimising diverse contexts while making mathematics meaningful. Such an analysis is especially important for texts that claim to portray both culturally relevant and critical pedagogical values (see Rampal (2015)). The Math-Magic textbook seems to go beyond the typical consumerist settings that are used in mathematics from a utilitarian perspective. Instead, they engage with rich contexts of students' (assumed) lived reality. Themes such as nature, games (e.g., carom, playing with bangles), stamps, animals, flags and different parts of India (location) are explored throughout the textbooks. Furthermore, as claimed by authors, there are some themes that address stereotypes about marginalised social groups and questioning ideas of power and oppression. However, looking at the text, neither do the teachers' guidelines nor the text itself pose any direct questions on how to engage with social issues. It is unclear how the teachers should discern those intended aspects from the text and operationalise them. For example, the chapter "Junkseller" (Book 5, Chapter 6, p. 62) uses the theme of a woman overcoming barriers to run a successful business. As described by Rampal (2015), this unit challenges both casteist and sexist notions of an entrepreneur. However, no explanation or background to the chapter is available to the teacher, leaving the task's interpretation to their discretion. Overall, very few tasks in the first seven chapters of Book 4 and Book 5 have themes that could possibly be used to talk about social issues. Only $11 \%$ of the tasks in case of Book 4 and $6 \%$ of those in Book 5 have this feature. Also, these issues are concentrated in the "special thematic chapters" (Rampal \& Subramanian, 2012, p. 69) of both the books - the Junk Seller and Fish Talewhere one theme is used across the chapter for multiple mathematical concepts.

Overall, by including wider context references (detailed contextual information, reference to art, poems, everyday life references), there is a clear attempt to move beyond the use of typical market-based context examples. The interaction of culture and mathematics 
has been explored by different scholars within the ethnomathematics and culturally relevant mathematics education tradition (d'Ambrósio, 2006; Greer et al., 2009). However, their translation into mathematical tasks (in stable text) as well as the subsequent enactment within lessons is much more complex. Furthermore, the authors also claimed to focus on addressing stereotypes about marginalised social groups and questioning ideas of power and oppression. In Rampal's (2015) description of the Math-Magic textbooks, she pointed out that the textbooks do not just use " "non-problematic' situations from the presumed everyday lives of pupils, but problematize daily life to enable 'problem posing instead of problem solving"' (Rampal, 2015, p. 107). She went on to claim that the textbook attempts to make students more critical and political and enable them to read the world in the sense described by Gutstein (2006). However, unlike Gutstein (2006), the textbook does not discuss the tension between teaching mathematics with the intention of giving students access to powerful mathematical ideas and the endeavour of explicitly discussing oppressive structures of the social world. It is also not clear whether these 'critical' elements examining socio-political issues of the world are aimed at students or whether they are meant to sensitise teachers to enable them to deal better with children from diverse backgrounds. Thus, while there is an attempt to include social justice perspectives, they seem to be limited in quantity and include very little explicit support for readers.

\subsection{Structure of the text: limited support for the teacher}

Focusing on the structure and prompts within the tasks, I discuss the elements in the textbook that help the reader navigate the textbook. Firstly, within the tasks, there is no explicit labelling to indicate pedagogical features such as instruction, solved examples, activities, puzzles or exercises. No fixed sequenced pattern from "introduction to explanation, examples and practice" is followed within the chapters. There are only a few repetitive names for tasks, such as 'practice time', 'activity' or 'find out' (Table 7). The rest of the task headers are related to the contextual theme of the task (e.g., To Bhimbhetka, Look Around, Magic Top, etc.).

In this way, explicit structuring elements, including names of tasks, are missing from the Math-Magic textbooks. So too is the more implicit support often provided within mathematics textbooks (e.g., repeated tasks, information and solved examples). As shown in Table 8 , in both the books, less than one-third of the total tasks include any prompts.

As Howson (2013) argued, textbooks not only provide tasks to be done, but also a "coherent framework for teachers" (p. 648). With respect to this, a huge shift is seen in these textbooks, which have abandoned traditional formats of presentation of mathematical ideas and taken on an alternative form. As shown above, neither explicit task headers are used to signal the pedagogical activity involved in the task nor does the sequencing of the

Table 7 Names and headers of textbook tasks

\begin{tabular}{lll}
\hline Task names & Book 4 & Book 5 \\
\hline Non-standardised names & 60 & 90 \\
Practice time & 3 & 17 \\
Find out & 9 & 4 \\
Activity time & 1 & 6 \\
Try it out/try this & 2 & 0 \\
Total number of tasks & 75 & 117 \\
\hline
\end{tabular}


Table 8 Percentage of support components within the tasks

\begin{tabular}{|c|c|c|c|c|c|}
\hline \multicolumn{2}{|l|}{ Prompts } & \multirow{2}{*}{$\begin{array}{l}\text { Book } 4 \\
\text { Total } \\
9\end{array}$} & \multirow{2}{*}{$\begin{array}{l}\text { Book } 4 \\
\% \\
12 \%\end{array}$} & \multirow{2}{*}{$\begin{array}{l}\text { Book } 5 \\
\text { Total } \\
13\end{array}$} & \multirow{2}{*}{$\begin{array}{l}\text { Book } 5 \\
\% \\
11 \%\end{array}$} \\
\hline Fact/information & $\begin{array}{l}\text { Non-eliciting components intended to provide } \\
\text { information/fact about the mathematical } \\
\text { object or procedure }\end{array}$ & & & & \\
\hline Solution/answer & $\begin{array}{l}\text { Non-eliciting components providing solved } \\
\text { examples, scaffolds or answers to the elicit- } \\
\text { ing questions }\end{array}$ & 15 & $20 \%$ & 36 & $31 \%$ \\
\hline Repetition & $\begin{array}{l}\text { Repeated eliciting components where the same } \\
\text { mathematical skill or process is to be used. } \\
\text { Tables to be filled by listing answers are } \\
\text { coded as repetition }\end{array}$ & 20 & $27 \%$ & 42 & $36 \%$ \\
\hline
\end{tabular}

tasks follow any structure of 'introduction to explanation, example and exercises', as typically seen in other mathematics textbooks in India. Even within the tasks, there is a lack of repetition, solved examples and mathematical information or facts, which are also typical to Indian mathematics textbooks. As discussed in the literature review, alternative forms of presentation, including a spiral curriculum, can be seen in many post-colonial contexts, such as Uganda, which has been attempting to change their textbook forms (Namukasa, 2018). These alternative formats of mathematical content reject the idea of a linear presentation and development of a mathematical idea.

\section{Discussion}

In this paper, a framework of voice-context-structure to highlight how Math-Magic integrates reform ideas within the textbooks has been applied. The particular focus on the social perspective of context, often neglected in textbook analysis, expands the modes of engagement introduced by Remillard (2011). This can be a useful framework for the development and analysis of future mathematics textbooks aimed at challenging traditional formats of mathematics teaching and learning. In the following subsections, I explain the importance of these textbooks as an operationalisation of reform ideals as well as argue for a need to move towards creating more educative materials that support teachers and learners in developing capacities to use such reformed texts.

\subsection{Textbook as a display of radical possibilities}

As highlighted earlier, these textbooks were the result of a progressively oriented curriculum framework, which was set up to challenge dominant ways of mathematics teaching. Textbook developers, including academic activists and non-governmental organisations, saw this opportunity of creating state-textbooks as a way of introducing critical pedagogical ideas. This paper has provided evidence that the Math-Magic primary mathematics textbooks have attempted to incorporate these reform ideals in unique ways. As prescribed by NCF-2005, the voice of the textbooks is used to open up the text and provide opportunities for its reader to approach mathematics in multiple ways. Furthermore, it has made an explicit attempt to create authentic real-life experience-based tasks for students to engage 
in, through undertaking rich contextual tasks with authentic stories, as well as by using contextual objects. In this way, it has promoted its critical and ethnomathematical ideals. As Syeed (2018) found, civil society activists were seemingly aware of the rare position of power that they had been afforded and used this opportunity to make the textbook, such that "it [was] embarrassing for anyone to go back to old styles of textbooks" (p. 555). The textbooks were, thus, not only created as a means of curriculum enactment, but also as an attempt to showcase how seemingly radical ideas can be included in the form of textbooks. Thus, the textbooks are a good compilation of tasks that challenge traditional formats of mathematics texts, especially useful for other post-colonial nations attempting similar goals. However, the findings also highlight some contradictions within the textbooks. For example, while there is an effort to move to authentic real-life contexts, there is also repeated use of traditional word problems. Moreover, while there is an effort to include diverse contexts from a social justice perspective, these are not always explicitly explained. Some of these tensions could also be a result of the textbook development process itself, which included the participation of both academic activists as well as bureaucrats, who had different opinions on the approaches (see Syeed (2018)). Thus, while the textbook was attempting to be radically different, its authors had to navigate concerns raised by bureaucrats, who opposed an explicit focus on social justice issues.

\subsection{Moving towards developing textbooks as educative materials for teachers}

While the textbook includes tasks purposefully to showcase how things can be done differently, as discussed above, the question is whether it pays sufficient attention to how these might become enacted in classrooms. While many alternative ways of presenting tasks and integration of context have been introduced into the individual tasks, explicit support for teachers is lacking. The biggest indicator of this is that almost all the tasks in the textbook have eliciting components and almost none is designed solely as non-eliciting tasks for providing information or solved examples. As Remillard (2011) discussed in her paper, different modes of engagement offer entry points for teachers so that the teachers still 'buy into' the textbooks. However, in the case of Math-Magic, which is a state-produced and mandated textbook series, the idea of what might work as an entry point for teachers seems to have been overlooked. Thus, the textbook authors do not seem mindful of how to integrate alternative ideas explicitly into it and possible ways of persuading teachers to use the texts.

Furthermore, while there is a need to celebrate effort made towards creating innovative textbooks, as Davis and Krajcik (2005) suggest, it is important to ensure that the texts endeavour to include educative elements explicitly. These elements bridge the gap in enabling teachers to access the rationale behind the pedagogies as well as providing information on how these can be used in classrooms. In India, where there are diverse classroom settings with diverse learners, student textbooks remain the most used curriculum resource, and hence, there is a critical need to interrogate how these can become pedagogical tools in creating meaningful classroom experiences (see Mili \& Winch, 2019). Clearly, by including teacher guidelines as footnotes within the Math-Magic textbooks, the authors are moving in the direction of providing 'support' to enable teachers to use the tasks. However, much more could be done to include more educative elements and entry points for them. With careful development of textbooks as strong pedagogical tools for teachers, we can start to challenge outmoded textbook cultures. 
Acknowledgements This work is part of the author's doctoral research project at the Faculty of Education, University of Cambridge. She wishes to thank Professor Kenneth Ruthven for his critical guidance and Professor Nidhi Singal for her unfailing support. Additional thanks go to the anonymous reviewers, whose comments helped in refining the article's conceptual framing and discussions. This work was made possible by doctoral scholarships awarded by the Cambridge Trust, Jawaharlal Nehru Memorial Trust and Cambridge International Scholarship.

Open Access This article is licensed under a Creative Commons Attribution 4.0 International License, which permits use, sharing, adaptation, distribution and reproduction in any medium or format, as long as you give appropriate credit to the original author(s) and the source, provide a link to the Creative Commons licence, and indicate if changes were made. The images or other third party material in this article are included in the article's Creative Commons licence, unless indicated otherwise in a credit line to the material. If material is not included in the article's Creative Commons licence and your intended use is not permitted by statutory regulation or exceeds the permitted use, you will need to obtain permission directly from the copyright holder. To view a copy of this licence, visit http://creativecommons.org/licenses/by/4.0/.

\section{References}

Ahl, L., \& Koljonen, T. (2017). When teacher guides speak "past" the teacher: Two Swedish mathematics teacher guides [Conference presentation]. ICME13, Hamburg.

Apple, M. W. (1992). Do the standards go far enough? Power, policy, and practice in mathematics education. Journal for Research in Mathematics Education, 23(5), 412-431.

Ball, D. L., \& Cohen, D. K. (1996). Reform by the book: What is - or might be - the role of curriculum materials in teacher learning and instructional reform? Educational Researcher, 25(9), 6-14.

Barcelos Amaral, R., \& Hollebrands, K. (2017). An analysis of context-based similarity tasks in textbooks from Brazil and the United States. International Journal of Mathematical Education in Science and Technology, 48(8), 1166-1184.

Ben-Peretz, M. (1990). The teacher-curriculum encounter: Freeing teachers from the tyranny of texts. SUNY Press.

Beswick, K. (2011). Putting context in context: An examination of the evidence for the benefits of "contextualised" tasks. International Journal of Science and Mathematics Education, 9(2), 367-390.

Borasi, R. (1986). On the nature of problems. Educational Studies in Mathematics, 17(2), 125-141.

Bowie, L. (2014). The interplay of the social, pedagogical and mathematical in a mathematics textbook. In M. Berger, K. Brodie, V. Frith, \& K. le Roux (Eds.), Proceedings of the Seventh International Mathematics Education and Society Conference (vol. 2, pp. 243-251). Hansa Print.

Brantlinger, A. (2011). Rethinking critical mathematics: A comparative analysis of critical, reform, and traditional geometry instructional texts. Educational Studies in Mathematics, 78(3), 395.

Bryant, B. R., Bryant, D. P., Kethley, C., Kim, S. A., Pool, C., \& Seo, Y.-J. (2008). Preventing mathematics difficulties in the primary grades: The critical features of instruction in textbooks as part of the equation. Learning Disability Quarterly, 31(1), 21-35. https://doi.org/10.2307/30035523

Clarke, P. (2001). Teaching and learning: The culture of pedagogy. Sage Publications.

Clarkson, P. (1993). Gender, ethnicity and textbooks. Australian Mathematics Teacher, 49(2), 14-16.

d'Ambrósio, U. (2006). Ethnomathematics: Link between traditions and modernity. BRILL.

Davis, E. A., \& Krajcik, J. S. (2005). Designing educative curriculum materials to promote teacher learning. Educational Researcher, 34(3), 3-14.

Doyle, W., \& Carter, K. (1984). Academic tasks in classrooms. Curriculum Inquiry, 14(2), 129-149.

Draisma, J. (2018). Mathematics textbook development for primary grades and its teachers in Mozambique. ZDM-Mathematics Education, 50(5), 949-963.

Eco, U. (1979). The role of the reader: Explorations in the semiotics of texts (Vol. 318). Indiana University Press.

Fan, L., \& Zhu, Y. (2007). Representation of problem-solving procedures: A comparative look at China, Singapore, and US mathematics textbooks. Educational Studies in Mathematics, 66(1), 61-75.

Fan, L., Zhu, Y., \& Miao, Z. (2013). Textbook research in mathematics education: Development status and directions. ZDM-Mathematics Education, 45(5), 633-646.

Fauvel, J. (1991). Tone and the teacher: Instruction and complicity in mathematics textbooks. In D. Pimm \& E. Love (Eds.), Teaching and learning school mathematics (pp. 111-121). Hodder \& Stoughton. 
Garcia, J. (1990). The portrayal of females and minorities in selected elementary mathematics series. School Science and Mathematics, 90(1), 2-12.

Gerdes, P. (1996). Ethnomathematics and mathematics education. In A. J. Bishop, K. Clements, C. Keitel, J. Kilpatrick, \& C. Laborde (Eds.), International handbook of mathematics education (pp. 909-943). Springer Science \& Business Media.

Gerofsky, S. (2004). A man left Albuquerque heading east: Word problems as genre in mathematics education. Peter Lang.

Gerofsky, S. (2010). The impossibility of 'real-life' word problems (according to Bakhtin, Lacan, Zizek and Baudrillard). Discourse: Studies in the Cultural Politics of Education, 31(1), 61-73.

Gravemeijer, K. P. E. (2014). Transforming mathematics education: The role of textbooks and teachers. In Y. Li, E. A. Silver, \& S. Li (Eds.), Transforming Mathematics Instruction (pp. 153-172). Springer.

Greer, B., Mukhopadhyay, S., Powell, A. B., \& Nelson-Barber, S. (2009). Culturally responsive mathematics education. Routledge.

Gutstein, E. (2006). Reading and writing the world with mathematics: Toward a pedagogy for social justice. Taylor \& Francis.

Herbel-Eisenmann, B. A. (2007). From intended curriculum to written curriculum: Examining the "voice" of a mathematics textbook. Journal for Research in Mathematics Education, 38(4), 344-369.

Herbel-Eisenmann, B. A., \& Wagner, D. (2007). A framework for uncovering the way a textbook may position the mathematics learner. For the Learning of Mathematics, 27(2), 8-14.

Hoogland, K., de Koning, J., Bakker, A., Pepin, B. E., \& Gravemeijer, K. (2018). Changing representation in contextual mathematical problems from descriptive to depictive: The effect on students' performance. Studies in Educational Evaluation, 58, 122-131.

Howson, G. (2013). The development of mathematics textbooks: Historical reflections from a personal perspective. ZDM-Mathematics Education, 45(5), 647-658.

Kumar, K. (1986). Textbooks and educational culture. Economic and Political Weekly, 21(30), 1309-1311.

Kumar, K. (1988). Origins of India's “textbook culture.” Comparative Education Review, 32(4), $452-464$.

Leshota, M. (2015). The relationship between textbook affordances and mathematics' teachers' pedagogical design capacity $(P D C)$ [Unpublished doctoral dissertation]. University of the Witwatersrand, Johannesburg.

Li, Y. (2000). A comparison of problems that follow selected content presentations in American and Chinese mathematics textbooks. Journal for Research in Mathematics Education, 234-241.

Mbekwa, M., \& Julie, C. (2009). Nature of contexts in school mathematical literacy textbooks. In M. Schäfer \& C. McNamara (Eds.), Proceedings of the Seventeenth Annual Meeting of Southern African Association for Research in Mathematics, Science and Technology Education (vol. 2, pp. 347-358). Rhodes University.

Mili, \& Winch, C. (2019). Teaching through textbooks: Teachers as practitioners of a discipline? Theory and Research in Education, 17(2), 181-201. https://doi.org/10.1177/1477878519862547

Milligan, L. O., Koornhof, H., Sapire, I., \& Tikly, L. (2018). Understanding the role of learning and teaching support materials in enabling learning for all. Compare: A Journal of Comparative and International Education, 49(4), 529-547.

Morgan, C. (2016). Studying the role of human agency in school mathematics. Research in Mathematics Education, 18(2), 120-141.

Mukherji, A., \& Mukul, A. (2009). Ma'am, the textbook has changed. The Times of India. Retrieved from https://timesofindia.indiatimes.com/india/Maam-the-textbook-has-changed/articleshow/5060338.cms

Nag Chowdhuri, M. (2021). Textures of transaction: Exploring the heterogeneity in primary teachers' engagements with mathematics textbooks in Delhi. Contemporary Education Dialogue, 18(1), 117-147.

Namukasa, I. K. (2018). Renewing textbooks to align with reformed curriculum in former colonies: Ugandan school mathematics textbooks. ZDM-Mathematics Education, 50(5), 937-948.

Namukasa, I. K., Kaahwa, J., Quinn, M., \& Ddungu, R. (2012). Critical curriculum renewal in Africa: The character of school mathematics in Uganda. In A. A. Abdi (Ed.), Decolonizing philosophies of education (pp. 177-191). Brill Sense.

NCERT. (2005). National curriculum framework 2005. Retrieved December 17, 2021, from https://ncert. nic.in/pdf/nc-framework/nf2005-english.pdf

NCERT. (2006a). Math-Magic: Textbook for mathematics for class I. Retrieved from https://ncert.nic.in/ textbook.php

NCERT. (2006b). Math-Magic: Textbook for mathematics for class III. Retrieved from https://ncert.nic.in/ textbook.php

NCERT. (2006c). Position paper: National focus group on curriculum, syllabus and textbooks. Retrieved from http://www.ncert.nic.in/new_ncert/ncert/rightside/links/pdf/focus_group/cst_final.pdf 
NCERT. (2007a). Math-Magic: Textbook for mathematics for class II. Retrieved from https://ncert.nic.in/ textbook.php

NCERT. (2007b). Math-Magic: Textbook for mathematics for class IV. Retrieved from https://ncert.nic.in/ textbook.php

NCERT. (2008). Math-Magic: Textbook for mathematics for class V. Retrieved from https://ncert.nic.in/ textbook.php

NCTM. (1989). Curriculum and evaluation standards for school mathematics. National Council of Teachers of Mathematics Commission on Standards for School.

Nyabanyaba, T. (1999). Whither relevance? Mathematics teachers' discussion of the use of "real-life" contexts in school mathematics. For the Learning of Mathematics, 19(3), 10-14.

OECD. (2004). The PISA 2003 assessment framework: Mathematics, reading, science and problem-solving knowledge and skills. Organisation for Economic Co-operation and Development Publishing.

Palm, T. (2006). Word problems as simulations of real-world situations: A proposed framework. For the Learning of Mathematics, 26(1), 42-47.

Rampal, A. (2015). Curriculum and critical agency: Mediating everyday mathematics. In S. Mukhopadhyay \& B. Greer (Eds.), Proceedings of the Eighth International Mathematics Education and Society Conference (vol. 1, pp. 83-110). Ooligan Press.

Rampal, A., \& Makar, K. (2012). Embedding authenticity and cultural relevance in the primary mathematics curriculum. The Twelfth International Congress of Mathematics Education. ICME-12, Seoul, Korea.

Rampal, A., \& Subramanian, J. (2012). Transforming the elementary mathematics curriculum: Issues and challenges. In R. Ramanujam \& K. Subramaniam (Eds.), Mathematics Education in India Status and Outlook Editors (pp. 63-88). Homi Bhabha Centre for Science Education Tata Institute of Fundamental Research.

Remillard, J. T. (2005). Examining key concepts in research on teachers' use of mathematics curricula. Review of Educational Research, 75(2), 211-246.

Remillard, J. T. (2011). Modes of engagement: Understanding teachers' transactions with mathematics curriculum resources. In G. Gueudet, B. Pepin, \& L. Trouche (Eds.), From text to “lived” resources (pp. 105-122). Springer.

Rezat, S. (2006). The structures of German mathematics textbooks. ZDM-Mathematics Education, 38(6), 482-487.

Rotman, B. (1988). Toward a semiotics of mathematics. Semiotica, 72(1-2), 1-36.

Sarangapani, P. (2003). Constructing school knowledge: An ethnography of learning in an Indian village. Sage Publications.

Schubring, G. (2017). Mathematics teaching in the process of decolonization. In K. Bjarnadóttir, F. Furinghetti, M. Menghini, J. Prytz, \& G. Schubring (Eds.), Dig where you stand: Proceedings of the Fourth International Conference on the History of Mathematics Education (pp. 349-368). Edizioni Nuova Cultura.

Sengupta, S. (2007). Politics is the new star of India's classrooms. The New York Times. Retrieved December 17, 2021, from https://www.nytimes.com/2007/08/15/world/asia/15india.html

Sood, S., \& Jitendra, A. K. (2007). A comparative analysis of number sense instruction in reform-based and traditional mathematics textbooks. The Journal of Special Education, 41(3), 145-157.

Subitha, V. G. (2018). Re-conceptualizing teachers' continuous professional development within a new paradigm of change in the Indian context: An analysis of literature and policy documents. Professional Development in Education, 44(1), 76-91.

Subrahmaniam, V. (2005). Making text-books a joy to read. The Hindu. Retrieved December 17, 2021, from https://www.thehindu.com/todays-paper/tp-national/making-text-books-a-joy-to-read/article27351223. ece

Syeed, E. (2018). Conflict between covers: Confronting official curriculum in Indian textbooks. Curriculum Inquiry, 48(5), 540-559.

Tripathi, P. (2006). Review: Mathematics text books. Contemporary Education Dialogue, 4(1), $142-151$.

Valverde, G. A., Bianchi, L. J., Wolfe, R. G., Schmidt, W. H., \& Houang, R. T. (2002). According to the Book. Springer Netherlands.

Van den Heuvel-Panhuizen, M. (2000). Mathematics education in the Netherlands: A guided tour. Freudenthal Institute Cd-Rom for ICME9. Utrecht University.

Verschaffel, L., Greer, B., \& De Corte, E. (2000). Making sense of word problems. Swets \& Zeitlinger Publishers.

Vijaysimha, I. (2013). 'We are textbook badnekais!': A Bernsteinian analysis of textbook culture in science classrooms. Contemporary Education Dialogue, 10(1), 67-97. 
Vithal, R., \& Skovsmose, O. (1997). The end of innocence: A critique of 'ethnomathematics'. Educational Studies in Mathematics, 34(2), 131-157.

Wagner, D. (2012). Opening mathematics texts: Resisting the seduction. Educational Studies in Mathematics, 80(1), 153-169.

Watson, A., \& Thompson, D. R. (2015). Design issues related to text-based tasks. In A. Watson \& D. R. Thompson (Eds.), Task design in mathematics education: An ICMI Study 22 (pp. 143-190). Springer.

Wijaya, A., van den Heuvel-Panhuizen, M., \& Doorman, M. (2015). Opportunity-to-learn context-based tasks provided by mathematics textbooks. Educational Studies in Mathematics, 89(1), 41-65.

Publisher's note Springer Nature remains neutral with regard to jurisdictional claims in published maps and institutional affiliations. 